УДК: 615.831(082)

DOI: http://dx.doi.Org/10.11603/mie.1996-1960.2016.2.6482

\title{
ОСОБЛИВОСТІ ВПЛИВУ ЕЛЕКТРОМАГНІТНИХ ХВИЛЬ ВИДИМОГО ДІАПАЗОНУ НА ЖИВІ ОРГАНІЗМИ
}

\author{
С. О. Ґуляр, 3. А. Тамарова \\ Інститут фрізіології імені О. О. Богомольця НАН України \\ Інтернаціональний медичний інноваційний центр
}

\begin{abstract}
Людина і тварини здатні сприймати світло не тільки за допомогою зорової системи, а й завдяки наявності специфічних екстраокулярних фоторецепторів. Такі фоторецептори взаємодіють з електромагнітними хвилями світлового діапазону на трьох стійких рівнях. Перший рівень - клітини, що мають чутливі до електромагнітних хвиль білки«сенсори». На вищому рівні електромагнітні хвилі взаємодіють з електромагніторецепторами, що представлені точками акупунктури та меридіанами, які слугують для підтримки електромагнітного гомеостазу організму. Найбільш складним рівнем є спеціалізовані нервові чутливі шляхи та центральні структури мозку, що контролюють через обмін речовин стійкість регуляції внутрішнього середовища організму.
\end{abstract}

Ключові слова: електромагнітні хвилі, точки акупунктури, гомеостаз, електромагніторецептори.

\section{ОСОБЕННОСТИ ВОЗДЕЙСТВИЯ ЭЛЕКТРОМАГНИТНЫХ ВОЛН ВИДИМОГО ДИАПАЗОНА НА ЖИВЫЕ ОРГАНИЗМЫ}

\author{
С. А. Гуляр, 3. А. Тамарова \\ Институт фризиологии имени А. А. Богомольца НАН Украины \\ Интернациональный медицинский инновационный центр
}

\begin{abstract}
Человек и животные способны воспринимать свет не только с помощью зрительной системы, но благодаря наличию специфических экстраокулярных фоторецепторов. Такие фоторецепторы взаимодействуют с электромагнитными волнами светового диапазона на трех устойчивых уровнях. Первый уровень - клетки, имеющие чувствительные к электромагнитным волнам белки-«сенсоры». На более высоком уровне электромагнитные волны взаимодействуют с электромагниторецепторами, которые представлены точками акупунктуры и меридианами, служащими для поддержания электромагнитного гомеостаза организма. Наиболее сложным уровнем являются специализированные нервные чувствительные пути и центральные структуры мозга, контролирующие через обмен веществ устойчивость регуляции внутренней среды организма.
\end{abstract}

Ключевые слова: электромагнитные волны, точки акупунктуры, гомеостаз, электромагниторецепторы.

\section{PECULIARITIES OF THE EFFECTS OF ELECTROMAGNETIC WAVES OF THE VISIBLE RANGE ON LIVING ORGANISMS}

\author{
S. A. Gulyar, Z. A. Tamarova \\ Bogomoletz Institute of Physiology of NAS Ukraine \\ International Medical Innovation Center
}

\begin{abstract}
Our experimental studies and a set of the published data allow one to conclude that animals and humans can perceive visible light not only with mediation of the visual sensory system, but also due to the existence of specific extraocular photoreceptors. In the latter system, we can classify three separate stable levels of interaction with exogeneous electromagnetic waves (EMW) of the visible range. The first, most simple level is the cellular level (cells possessing sensor proteins reactable to EMW). The next, higher level is based on interaction of EVW with specialized electromagnetoreceptors; acupuncture points and meridians providing the maintenance of electromagnetic homeostasis of the organism cam be considered such a receptor system. Finally, the most complex level involves specialized sensory pathways and central brain structures controlling general homeostasis of the organism with mediation of the processes of metabolism.
\end{abstract}

Key words: electromagnetic waves, acupuncture points, homeostasis, electromagnetoreceptors.

C. С. О. Гуляр, 3. А. Тамарова 
Введение. Фундаментальные законы поляризованного света сформулировал французский ученый Араго Доминик Франсуа, который в 1811 г. открыл хроматическую поляризацию света и наблюдал вращение плоскости поляризации в кварце. Применение поляризованного света в медицине началось в конце XX века, когда была понята биологическая роль явления поляризации лазерного излучения. В середине 80-х годов прошлого века появились светотерапевтические аппараты, излучающие видимый некогерентный поляризованный свет (ПАЙЛЕР-свет).

В настоящее время с помощью локального воздействия ПАЙЛЕР-светом успешно лечатся травмы, ожоги, аллергии, воспаления, нарушения иммунной системы, а также разные болевые синдромы [4]. Имеются очень обнадеживающие клинические результаты применения ПАЙЛЕРсвета в лечении пациентов с неврологическими, стоматологическими, урологическими, гинекологическими заболеваниями.

Полагают, что в основе терапевтического эффекта ПАЙЛЕР-света лежат процессы фотомодификации крови, способствующие восстановлению ее функциональных свойств и периферического кровообращения, стимуляции обменных и пролиферативных процессов в тканях и органах, нормализации окисления ненасыщенных жиров, повышению продуцирования антиоксидантов, активации различных компонентов иммунной системы и восстановлению баланса в звеньях вегетативной нервной системы $[4,20]$. Такой механизм лечебного действия ПАЙЛЕР-света, несомненно, существует, но, как показали данные последних исследований, обнаружены и другие механизмы воздействия ПАЙЛЕР-света на живые организмы.

По-видимому, живые организмы имеют специфические сенсорные системы, способные воспринимать поляризованный свет. В 1846 г. Г. Хайдингер обнаружил, что глаз человека обладает чувствительностью к поляризованному свету, благодаря чему, как позже выяснилось, увеличивается контрастность изображения. Доказано, что различные представители животного мира (насекомые, рыбы, моллюски) используют поляризованный свет для ориентирования в пространстве, улучшения цветовосприятия и коммуникации. Между тем, имеется много фактов, позволяющих предполагать, что кроме зрительной системы, для восприятия внешних электромагнитных волн (ЭМВ), существуют пока еще неизвестные сенсорные системы.
Основная часть. Установлено, что в тканях организма, в том числе в клетках кожи, существуют специализированные протеины, которые служат «сенсорами» ЭМВ оптического диапазона. Благодаря им клетки способны реагировать на изменения частоты и амплитуды ЭМВ запуском генетических программ, стабилизирующих функции организма [23]. Чувствительность к ЭМВ зависит от функционального состояния клеток: она выше в патологически измененных тканях [16]. Среди «сенсоров» клеток к ЭМВ в настоящее время выявлены: протеазы - активаторы плазминогена (PAS-протеины), протеины теплового шока (hspпротеины), протеины-криптохромы, энцефалопсин и некоторые другие пептиды.

Фундаментальная роль PAS-протеинов [23] в том, что они, находясь внутри клеток, служат сенсорами действия ЭМВ оптического диапазона, сенсорами изменений напряжения кислорода, окислительно-восстановительных потенциалов и некоторых других сигналов. PAS-протеины реагируют на эти сигналы, определяя изменения в системе транспорта электронов. Благодаря этому PAS-протеины являются молекулами, чувствительными к любым изменениям обмена веществ, и входят в состав потенциал-управляемых ионных каналов, где играют роль «системы раннего оповещения» о любом снижении уровня энергии в клетке. У млекопитающих «сенсорами» клеток к ЭМВ являются также экстраокулярные фоторецепторы протеины-криптохромы, которые рассматриваются как вероятные рецепторы света биологических часов. Кроме того, в клетках гипоталамуса, а также ряда других структур мозга млекопитающих идентифицирован гомолог фоточувствительных пептидов сетчатки и эпифиза - энцефалопсин [1], который может участвовать в фоторецепции мозга.

Фоторецепторные специфические протеины обнаружены в эпифизе млекопитающих. Также доказана, бесспорно, высокая магниточувствительность эпифиза. К сожалению, пока не все экстраокулярные фоторецепторы в мозгу человека идентифицированы, а их функции определены. Предполагают [15], что в орбитофронтальной коре существуют фоторецепторы, играющие решающую роль в иммунорегуляции. Это доказано выраженным клиническим эффектом у пациентов с ревматоидным артритом при их лечении воздействием поляризованного видимого света на область фронтальной коры через свод черепа [15]. Таким образом, имеется достаточно эксперимен- 
тальных данных, позволяющих считать, что живые организмы способны воспринимать ЭМВ оптического диапазона, помимо органа зрения, также на клеточном уровне с помощью фотосенситивных протеинов. Роль ПАЙЛЕР-света в этом механизме пока не доказана.

Не исключено, что одной из систем восприятия поляризованного света являются расположенные в разных участках кожи тела точки акупунктуры и меридианы, связанные в единую энергетическую систему. Известно, что в точках акупунктуры имеются большие скопления разнообразных рецепторов, реагирующих не только на введение игл, но и на тепло, холод, давление и другие воздействия. Современные исследования механизмов акупунктуры показали, что физиологические ответы и лечебные эффекты, а также определенные сенсорные ощущения могут быть получены при воздействии на точки акупунктуры электромагнитной энергии (свет, магнитные, электрические поля), локальных областей вакуума, то есть действием на организм природных физических процессов. Недавно обнаружено, что точки акупунктуры можно эффективно стимулировать электромагнитными полями разных частот, например, низкоинтенсивными микроволнами [11].

Это позволило предположить, что точки акупунктуры являются рецепторами системы контроля электромагнитного гомеостаза организма. Через эту систему контролируются факторы внешней (электромагнитные поля Солнца и Земли, метеофакторы) и внутренней (обмен веществ) среды. В случаях значительных отклонений этих факторов от нормы структуры гипоталамуса запускают адаптивные механизмы, компенсирующие их отрицательные влияния на энергетические процессы в организме $[9,12,28]$. Большой интерес представляет исследование воздействия ПАЙЛЕР-света на точки акупунктуры.

В последнее время накоплен успешный опыт в лечении болевых синдромов воздействием ПАЙЛЕР-света на зоны тела, где расположены специфические противоболевые точки акупунктуры [3, 17, 21, 25]. Однако из-за субъективной оценки боли человеком и невозможности количественно определить ее интенсивность до и после лечения, клинические наблюдения не позволяют получить статистически достоверные данные об интенсивности и продолжительности анальгезии, а также выявить режимы ПАЙЛЕР-света, вызывающие максимальный анальгетический эффект. Ответы на эти вопросы могут дать лишь эксперименты на животных, где есть возможность точной количественной оценки боли, а главное, отсутствует психогенный фактор, неизбежно сопровождающий исследования болевых реакций у человека.

Известно, что у всех животных существуют точки акупунктуры и соединяющие их меридианы, которые по топографии и структурно-функциональным свойствам полностью совпадают с аналогичной системой у человека [21]. Это позволяет использовать животных для изучения механизмов лечебного эффекта воздействия на точки акупунктуры [2, 5, 22].

В наших экспериментах на мышах с искусственно созданным очагом тонической боли (формалиновый тест) было изучено влияние ПАЙЛЕРсвета аппарата БИОПТРОН на поведенческие реакции [13]. Оказалось, что ПАЙЛЕР-свет при воздействии на точки акупунктуры статистически достоверно ослабляет болевую поведенческую реакцию (лизание очага боли), но увеличивает продолжительность неболевых поведенческих реакций (сон, еда). При этом анальгетический эффект зависел как от выбора точки акупунктуры, так и от продолжительности воздействия ПАЙЛЕР-светом. Мы обнаружили, что в пределах выбранных интервалов времени $(4,8,10$ мин) максимальная анальгезия (50\%) наблюдалась после 10-минутного воздействия ПАЙЛЕР-светом на точку акупунктуры Е-36, но она была слабее при воздействии на точку акупунктуры V-60. Воздействие света на участок кожи, не содержащий противоболевых точек акупунктуры, оказалось неэффективным. Клинические исследования подтверждают специфичность точек акупунктуры относительно неакупунктурных точек. При сравнении плацебо и реальной акупунктуры положительный эффект отмечен соответственно у 30 и 70\% больных с хроническим болевым синдромом [14], что служит одним из доказательств того, что точки акупунктуры являются специфическими зонами кожи, обладающими особыми рецепторными свойствами.

Механизмы анальгетического действия ПАЙЛЕР-света пока не изучены. Можно считать, что в результате воздействия поляризованным светом на точки акупунктуры запускаются собственные противоболевые системы мозга, что приводит к подавлению передачи болевых импульсов на нейронном уровне. Такой механизм в настоящее время доказан в случае воздействия 
на точки акупунктуры электрическим током или низкоинтенсивным электромагнитным излучением микроволнового диапазона $[24,26]$. Показано участие в акупунктурной анальгезии опиоидной, моноаминергических и пептидергических эндогенных противоболевых систем мозга.

Реализация воздействия ПАЙЛЕР-светом на точки акупунктуры через рецепторы и центральные структуры нервной системы является, по-видимому, не единственным путем. Традиционные теории акупунктуры считают, что точки акупунктуры и меридианы передают «жизненную энергию» между отдельными частями и органами тела. Современные исследователи предполагают, что морфологической основой для циркуляции «жизненной энергии», а по сути движения электрических токов являются электрически заряженные продольные цепочки протеинов, в частности, коллагеновые волокна, а «энергетический ток» меридианов обеспечивается миграцией электрических зарядов вдоль интерстициальных пространств. Экспериментально показано, что в коже человека, лежащей на линиях меридианов, существуют синаптические контакты между тучными клетками, афферентными пептидергическими (субстанция Р) и эфферентными волокнами. Эти зоны заполнены широкими пучками коллагеновых и ретикулиновых волокон.

Это дает основание предполагать, что при воздействии ЭМВ на точки акупунктуры их сигналы не только трансформируются в группы потенциалов действия, идущих по чувствительным волокнам соматосенсорной системы в мозг, но и в виде потоков энергии распространяются в организме по соединительной ткани, образующей систему меридианов. По-видимому, потенциалы действия, распространяющиеся по классическим путям центральной нервной системы, в первую очередь управляют работой нейроэндокринных структур, контролирующих функции висцеральных систем (кровообращение, дыхание, выделение и т.д.) поддержания общего гомеостаза организма. В то же время потоки энергии, распространяющиеся по системе интерстициальных пространств организма, служат для поддержания оптимальных электромагнитных параметров его внеклеточных и межклеточных сред - электромагнитного гомеостаза.

Направление циркуляции «энергетических токов» в меридианах определяется разницей концентрации свободных ионов, содержащихся в интерстициальной жидкости, где они движутся от большего электрического потенциала к меньшему.
Существование в коже продольно организованных структур подтверждают исследования распределения потоков видимого света, показавшие что под кожей человека имеются участки проведения света в одном направлении, совпадающие с направлением меридианов [7]. Роговой слой кожи над линиями меридианов примерно вдвое тоньше, чем в коже вне меридианов. Каждый меридиан имеет ширину около 1 мм и отличается от окружающей кожи более низким сопротивлением, что создает условия предпочтительного распространения электрических токов вдоль этих путей.

Существует гипотеза о том, что в организме ведущую роль в формировании меридианов и передаче по ним энергии в виде ионов, электронов и протонов играет мышечно-сухожильная ткань. Соединительная ткань не только объединяет органы и системы в единое целое, но, обладая свойствами генерировать и передавать энергию, может функционировать как коммуникационная сеть, способная распределить электрические потоки энергии между различными частями и внутри каждой части тела. Есть мнение, что меридианы представляют собой пути, возникающие между различными областями тела эмбриона, по которым развивается нервная, кровеносная, лимфатическая и мышечная системы и которые у взрослого объединяют органы в единое функциональное целое. Согласно недавней гипотезе [6], материальной основой меридианов являются находящиеся в холестерической фазе жидкие кристаллы, чувствительные к физическим воздействиям. При этом акупунктурная система представляет собой непрерывную сеть жидкокристаллических волокон коллагена, образующих основной объем соединительной ткани. Среди этих волокон лежат клетки, способные воспроизводить и усиливать поступающие к ним потоки энергии разных частот. Подобного рода спонтанные осцилляции электрических потенциалов и склонность к образованию на поверхности нитевидных потоков зарядов обнаружена и в классических кристаллах германия [18]. Волокна коллагена разделены слоями воды, которая создает проводящие протонные пути для быстрой интеркоммуникации всех частей тела. Доказано, что проводимость в тканях энергии высокочастотных ЭМВ главным образом зависит от содержания воды. Ткани с высоким содержанием воды, такие как мышцы и кожа, имеют большую проводимость высоких частот, чем жировая или костная ткань. Следовательно, мышцы и кожа ведут себя по отношению к электромагнитным сигналам 


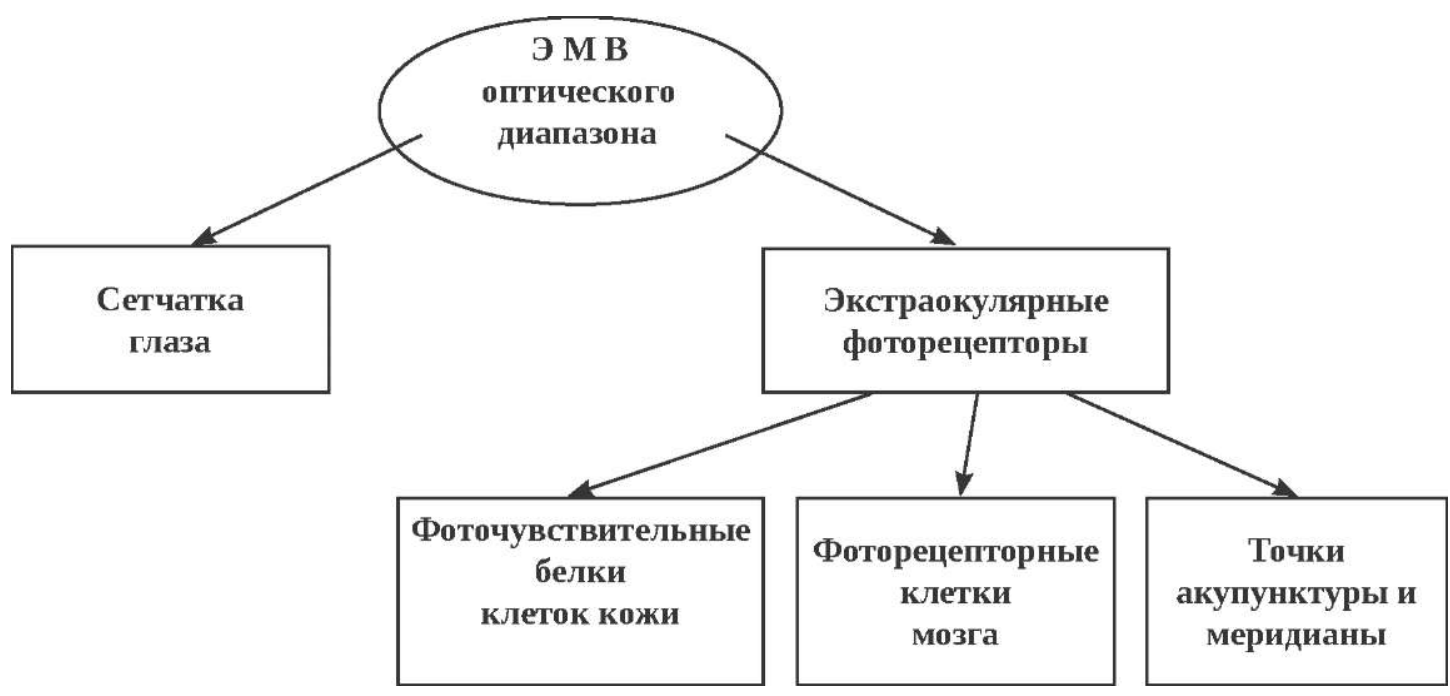

Рис. 1. Схема действия ЭМВ оптического диапазона на живые организмы

как фильтры с низким сопротивлением [10]. Bсе это позволяет электромагнитной функциональной системе организма действовать как единая когерентная структура.

У 45 \% людей меридианы обладают сенсорной чувствительностью, проявляющейся в возникновении «вызванных ощущений» и изменениях локального кровотока. Эта чувствительность у слабых и больных людей значительно выше, чем у здоровых. Она также зависит от наследственности. В естественных условиях меридианы и точки акупунктуры, по-видимому, реагируют на напряженность магнитных и электрических полей Земли, меняющихся в зависимости от времени суток, сезона года, климата и других факторов окружающей среды.

Выводы. 1. Человек и животные способны воспринимать свет не только посредством зрительной системы, но и благодаря наличию специфических экстраокулярных фоторецепторов.

2. Среди экстраокулярных фоторецепторов можно выделить три устойчивых уровня взаимодействия с экзогенными электромагнитными волнами оптического диапазона.

- Первый уровень - наиболее простой: уровень клеток, имеющих белки-«сенсоры» для ЭМВ.

- За ним следует более высокий уровень: взаимодействие ЭМВ с электромагниторецепторами точки акупунктуры и меридианы, служащие для поддержания электромагнитного гомеостаза организма.

- И, наконец, наиболее сложный уровень специализированные чувствительные пути и центральные структуры мозга, контролирующие через обмен веществ общий гомеостаз организма.

\section{Литература.}

1. Blackshaw S. Encephalopsin: a novel mammalian extraretinal opsin discretely localized in the brain / Blackshaw S., Snyder S. H. // J. Neurosci. - 1999. - № 10. - P. 3681-3690.

2. Cao Q. Effects of electroacupuncture at neiguan on myocardial microcirculation in rabbits with acute myocardial ischemia / Cao Q., Liu J., Chen S., Han Z. // J. Tradit. Chin. Med. - 1998. - № 2. - P. 134-139.

3. Грохольский А. П. Применение видимого поляризованного света при лечении стоматологических заболеваний. В кн: БИОПТРОН: Теория, клиника, перспективы / Грохольский А. П., Грохольская Л. А., Макашова Т. В. и др. К., 1999. - С. 52 - 58.

4. Гуляр С. А. Двойная технология сохранения здоровья в экологически неблагоприятных условиях: синергизм ПАЙЛЕР-света и антиоксидантов. В кн: БИОПТРОН: Теория, клиника, перспективы. - К., 1999. - С. 6-21.

5. Han S. H. Inhibitory effects of electroacupuncture on stress responses evoked by tooth-pulp stimulation in rats / Han 5. H., Yoon S. H., Cho Y. W. et al. // Physiol. Behav. - 1999. - № 2. - P. 217-222.

6. Ho M. W. The acupuncture system and the liquid crystalline collagen fibers of the connective tissues / Ho M. W., Knight D. P. // Amer. J. Chin. Med. - 1998. - № 3-4. - P. 251-263.

7. Казначеев В. П. Биоинформационная функция естественных электромагнитных полей / Казначеев В. П., Михайлова Л. П. - Новосибирск : Наука, 1985. - 180 с. 
8. Клименко П. М. Применение аппарата «БИОПТРОН» при лечении хронического простатита и его осложнений. / В кн: БИОПТРОН: Теория, клиника, перспективы. - К., 1999. - С. 67-72.

9. Колбун Н. Д. Теория и практика информационно-волновой терапии. - К.: Биополис, 1996. - 268 с.

10. Lepelaar E. S. Electromagnetic pulse distortion in living tissue // Med. Biol. Eng. Comput. - 1996. - № 3. - P. $213-220$. 11. Лиманский Ю. П. Гипотеза о точках акупунктуры как полимодальных рецепторах системы экоцептивной чувствительности // Физиол. журн. - 1990. - № 4. - С. 115-122.

12. Лиманский Ю. П. Подавление ноцицептивных реакций у мышей низкоинтенсивным микроволновым воздействием на точку акупунктуры / Лиманский Ю. П., Тамарова 3. А., Бидков Е. Г., Колбун Н. Д. // Нейрофизиология. - 1999. - № 4. - С. 290-294.

13. Лиманський Ю. П. Дослідження анальгетичної дії поляризованого світла / Лиманський Ю. П., Тамарова 3. А., Гуляр С. О., Бідков Е. Г. // Фізіол. журн. - 2000. - № 6. - С.105-111.

14. Lewith G. T. On the evaluation of the clinical effects of acupuncture / Lewith G. T., Machin D. // Pain. - 1983. № 2. - P. 111-127.

15. Madrid L. Cortical photostimulation with filtered visible light as a treatment for rheumatoid arthritis / Madrid L., Issacharoff M., Bianchi J. et al. // Scand. J. Rheumatol. - 1998. - № 6. - 454-457.

16. Muehsam D. J. The sensitivity of cells and tissues to exogenous fields: effects of target system initial state / Muehsam D. J., Pilla A. A. // Bioelectrochem. Bioenerg. - 1999. - № 1. - P. 35-42.

17. Otsuka H. Polarized light irradiation near stellate ganglion in a patient with Raynauld,s sign / Otsuka H., Okubo K., Imai M., Kasemo S., Kemmotsu O. // Masui. - 1992. - № 11. - P. 1814-1817.

18. Parisi J. Self-organization in semiconductor physics // Biosystems. - 1997. - № 2-3. - P.145-152.

19. Пресман А. С. Электромагнитные поля и живая природа - М.: Наука, 1968. - 268 с.

20. Samoilova K. A. Effects of Lower Power Light on Biological Systems / Samoilova K. A., Obolenskaya K. D., Vologdina A. V. et al. - Berlins - Proceed. of SPIE. 3569, 1998. - P. 90-103.

21. Schoen A. M. (Ed). Veterinary Acupuncture: Ancient Art to Modern Medicine. - Published by American Veterinary Publications, Inc., Goletaю - 1994. - 707 p.

22. Shankar N. Electroacupuncture, morphine and clonidine: a comparative study of analgesic effects . Shankar N., Varshney A., Bhattacharya A., Sharma K. N. // Indian. J. Physiol. Pharmacol. - 1996. - № 3. - P. 225-30.

23. Taylor B. L. PAS domains: internal sensors of oxygen, redox potential, and light/ Taylor B. L., Zhulin I. B. // Microbiol. Mol. Biol. Rev. - 1999. - № 2. - P. 479-506.

24. Ulett G. A. Electroacupuncture: mechanisms and clinical application / Ulett G. A., Han S., Han J. S. // Biol. Psychiatry. 1998. - № 2. - Р. 129-138.

25. Влахова И. О. Применение светотерапии аппаратом «Биоптрон-1» в лечении пациентов с сахарным диабетом / В кн.: БИОПТРОН: Теория, клиника, перспективы. - К. : Цептер, 1999. - С. 41 - 44.

26. Wang J. Effects of naloxone on the changes of pain threshold and contents of monoamine neurotransmitters in rat brain induced by EA / Wang J., Wang S., Zhang W. // J. Tradit. Chin. Med. - 1991. - № 4. - P. 286-290.

27. Xu G. Y. Reversal of the inhibitory effect of electroacupuncture on the nociceptive response of neurons in parafascicular nucleus by naloxone in acute arthritic rats / Xu G. Y., Duanmu Z., Yin Q. // Sheng Li Hsueh Pao. - 1994. - № 5. - P. 427-434. 28. Zukauskas G. Bioelectrical homeostasis as a component of acupuncture mechanism / Zukauskas G., Dapsys K. // Acupunct. Electrother. Res. - 1991. - № 3. -4. - P. 117-126. 